\title{
Streptococcus pneumoniae Upper Respiratory Carriage in Costa Rican Children with Otitis Media before the Introduction of the Heptavalent Conjugated Vaccine in the National Immunization Program
}

\author{
Catalina Ulloa $^{1}$, Alfonso Pereira ${ }^{1}$, Carolina Soley ${ }^{1}$, Nurith Porat $^{2}$, Arturo Abdelnour ${ }^{1}$, \\ Ron Dagan ${ }^{2}$, Adriano Arguedas ${ }^{1,3^{*}}$ \\ ${ }^{1}$ Instituto de Atención Pediátrica, San José, Costa Rica; ${ }^{2}$ Pediatric Infectious Disease Unit, Soroka University Medical Center and the \\ Faculty of Health Sciences, Ben-Gurion University of the Negev, Beer-Sheva, Israel; ${ }^{3}$ Universidad de Ciencias Médicas, San José, \\ Costa Rica. \\ Email: aabdelnour@iped.net
}

Received February $28^{\text {th }}, 2013$; revised March 29 th $^{\text {th }}$ 2013; accepted April $8^{\text {th }}, 2013$

Copyright (C) 2013 Catalina Ulloa et al. This is an open access article distributed under the Creative Commons Attribution License, which permits unrestricted use, distribution, and reproduction in any medium, provided the original work is properly cited.

\begin{abstract}
Objective: The aim of this study was to analyze the NP/OP S. pneumoniae serotype distribution and potential vaccine coverage in Costa Rican children with Otitis Media (OM) before the introduction of PCV-7 in the National Immunization Program (NIP). Methods: Between 2002 and 2006, NP and OP samples were obtained from 641 children from 6 to 79 months of age, at the time of OM diagnosis. S. pneumoniae serotyping and antimicrobial susceptibility were performed. Results: 386 S. pneumoniae isolates were recovered. The most common S. pneumoniae serotypes (ST) were: ST 6 B, ST 14, ST 19F. Penicillin non-susceptibility was observed among $57 \%$ of the isolates obtained from children $<$ 24 months of age. $15 \%$ strains were multidrug resistant. Potential vaccine coverage was: PCV-7: $60 \%$; PCV-10: 62\%; and PCV-13: $76 \%$ and against penicillin non-susceptible and multidrug resistant isolates was: PCV-7; 59\% and $83 \%$, respectively; PCV-10: 60\% and 85\%, respectively and PCV-13: 74\% and 96\%, respectively. Conclusions: S. pneumoniae was isolated from the NP and/or OP in the majority (59\%) of studied children with OM. At a statistical significant level, only serotype 3 was more frequently isolated among children $>24$ months of age. Antibiotic non-susceptibility and MDR were significantly higher in children $<24$ months of age. This study demonstrates that PCV-13 offers the highest potential vaccine coverage and serves to assess the impact of introduction of one of the conjugated vaccines in the NIP in Costa Rica.
\end{abstract}

Keywords: Streptococcus pneumoniae; Serotypes; Nasopharynx; Oropharynx; Pneumococcal Conjugated Vaccine

\section{Introduction}

Streptococcus pneumoniae is a major cause of morbidity and mortality in children, especially in those younger than 5 years of age living in developing countries [1-3]. The main reservoirs of this bacterial pathogen are the nasopharynx (NP) and the oropharynx (OP), from which it can spread directly to adjacent mucosal tissues to cause otitis media (OM) or pneumonia, or through the blood stream to other sites causing sepsis, meningitis or disseminated focal infections. S. pneumoniae is usually isolated in $25 \%$ to $60 \%$ of NP cultures obtained from healthy children [1-6].

*Currently Dr. Adriano Arguedas works at Pfizer Inc.
Nasopharyngeal colonization with $S$. pneumoniae is a pre-requisite for local and systemic disease. Several studies conducted in Israel [6], South Africa [7], Pakistan [8] and Brazil [9] confirm that nasopharyngeal colonization with S. pneumoniae in young children may predict the serotype distribution and antimicrobial susceptibility of the strains producing invasive disease. In a prospective study performed in Costa Rica, $79.2 \%$ of children in whom NP cultures were obtained weekly had at least one positive culture for $S$. pneumoniae during the first year of life [10].

Streptococcus pneumoniae carriage is highest among infants and young children (especially in those $<24$ months of age) and decreases with age [11]. In the gen- 
eral population in the United States and other industrialized countries, the mean age of $S$. pneumoniae acquisition is approximately 6 months $[12,13]$, whereas in developing countries, it is as early as 2 to 3 months of age $[14,15]$.

During the past 15 years, a worldwide increase of antimicrobial resistance by $S$. pneumoniae has been observed, particularly among strains colonizing the respiratory tract or producing respiratory tract infections [1618]. Antibiotic-resistance involve mainly few serotypes (6A, 6B, 9V, 14, 19A, 19F and 23F).

Numerous studies have shown that $S$. pneumoniae conjugate vaccines (PCVs) reduce nasopharyngeal carriage of vaccine serotypes [19-27], however, concerns have been raised because of the increase of certain nonvaccine serotypes such as $19 \mathrm{~A}, 7 \mathrm{~F}$ and 3 following the introduction of PCV-7 into the NIP of different countries $[28,29]$.

PCV-7 was introduced in Costa Rica in 2004 but its use was limited to high risk patients and the private sector, until 2009 when it was introduced into the NIP (National Immunization Program). Based on the number of PCV-7 doses distributed, it is estimated that less than 5\% of the annual birth cohort were fully vaccinated with PCV-7 before NIP introduction.

Our main objectives in this study were 1) to analyze the prevalence and serotype distribution of S. pneumoniae NP and/or OP colonization among Costa Rican children from 6 to 79 months of age, with OM before the introduction of PCV-7 in the NIP of Costa Rica; 2) analyze the antimicrobial susceptibility patterns among the recovered NP and OP S. pneumoniae serotypes isolated; and 3) calculate the potential vaccine coverage against the isolated serotypes with the three currently available PCVs in Latin America (PCV-7, PCV-10 and PCV-13).

\section{Materials and Methods}

\subsection{Study Population}

As part of various clinical trials of antimicrobial drug efficacy for OM conducted between 2002 and 2006, a total of 641 Costa Rican children, aged 6 - 79 months, with OM and in whom an NP and/or OP culture were obtained at the time of OM diagnosis, were included in the present analysis.

Participants with at least one of the following ear finding were included in the current analysis: purulent otorrhea of $<24$ hour duration, at least one otoscopic signs of middle ear effusion: decreased or absent tympanic membrane (TM) mobility; and at least one indication of acute inflammation (ear, pain, marked redness of $\mathrm{TM}$ or distinct fullness or bulging $\mathrm{TM}$ ) and clinical symptoms of OM (fever, tugging or irritability). Participants were excluded from the analysis if the TM was perforated for $\geq 48$ hours; if tympanic tubes were present; and if congenital craniofacial abnormalities or any known immunodeficiency were notified.

All the study protocols were approved by an Institutional Review Board and informed consent was obtained from the parents or legal guardian of each study participant before enrollment.

\subsection{Nasopharyngeal and Oropharyngeal Sampling}

NP and/or OP samples were obtained in every participant at the baseline visit. Samples were obtained following a deep swab in the NP or OP with a flexible pediatric culture device (Copan Diagnostics Inc, Corona, $\mathrm{CA}^{\circ}$ ). Once $\mathrm{NP}$ and/or OP samples were collected, they were immediately placed in an Amies medium without charcoal (Copan Diagnostics Inc, Corona, $\mathrm{CA}^{\odot}$ ) and transferred to the Research Laboratory for processing. In patients in whom the same $S$. pneumoniae serotype was isolated from both NP and/or OP, only data from NP was included in the analysis.

\subsection{Microbiology}

NP and/or OP samples were inoculated onto regular blood agar, blood agar with $5 \mu \mathrm{g}$ of gentamicin, chocolate agar, McConkey agar and manitol salt agar for incubation at $37^{\circ} \mathrm{C}$ in $5 \% \mathrm{CO}_{2}$ environment for $18-72$ hours at the bacteriology units of the Centro de Investigaciones Clínicas in Costa Rica. If growth was present, identification was performed by standard procedures. S. pneumoniae identification was performed following the Clinical Committee for Clinical Laboratory Standards by standard procedures [30].

\subsection{Antimicrobial Susceptibility}

Susceptibility testing for erythromycin and trimethoprimsulfametoxazole (TMP/SMX) was done by Kirby-Bauer disk diffusion. Susceptibility testing for penicillin, ceftriaxone, levofloxacin, amoxicillin, amoxicillin-clavulanate (AM-CL), was determined by minimal inhibitory concentration (MIC) by means of the E-test (PDM Epsilometer, AB Biodisk, Solma, Sweden). Because of the characteristics of the strips and as recommended by the manufacturer, when the E-test method was used, MIC values intermediate between two marks were rounded up to the next higher 2-fold dilution. Interpretation of the results was performed according to the National Committee for Clinical Laboratory Standards recommendations [30].

$\mathrm{MIC}_{50}$ was defined as the MIC of a given antimicrobial drug that inhibited growth of $50 \%$ of the isolates, and $\mathrm{MIC}_{90}$ was defined as the MIC of a given antimicro- 
bial drug that inhibited growth of $90 \%$ of the isolates. $S$. pneumoniae isolates with an $\mathrm{MIC} \leq 0.06 \mathrm{mg} / \mathrm{L}$ were considered susceptible to penicillin; isolates with a MIC value between $0.125 \mathrm{mg} / \mathrm{L}$ and $1.0 \mathrm{mg} / \mathrm{L}$ were considered intermediate to penicillin and those with a MIC value $\geq$ $2.0 \mathrm{mg} / \mathrm{L}$ were defined as penicillin resistant.

Multidrug resistant (MDR) isolates were defined as those strains resistant to $\geq 3$ different antimicrobial classes.

\subsection{Streptococcus pneumoniae Serogrouping and Serotyping}

Initially all isolates were stored at $-70^{\circ} \mathrm{C}$ at Centro de Investigaciones Médicas in Costa Rica in Micro Bank vials (Pro-Laboratory Diagnostics, Austin, TX) and then shipped on dry ice or on transport media at room temperature to the Research Laboratory of the Pediatric Infectious Diseases Unit at Soroka University Medical Center, Beer-Sheva, Israel. Serogrouping and serotyping of all S. pneumoniae isolates were performed in BeerSheva Israel by the Quellung reaction with antisera from Statens Serum Institute, Copenhagen, Denmark [31].

\subsection{Statistical Analysis}

The statistical package EPI INFO (version 3.5.3) was used to test difference on S. pneumoniae serotyping distribution and microbial susceptibility between children aged $\leq 24$ months and $>24$ months (by the Fisher exact test, Yates or square test, as appropriate). A $P$ value of $<$ 0.05 was considered significant.

Proportion of coverage by PCV-7, PCV-10 and PCV13 were calculated by proportion of serotypes included in the vaccines of all serotypes detected in children. No cross protection between serotypes was assumed.

\section{Results}

Between 2002 and 2006, simultaneous NP and OP samples were obtained from 641 Costa Rican children with $\mathrm{OM}$. The mean age \pm standard deviation (SD) was 23 months \pm 16.5 months and 393 (61\%) children were $\leq 24$ months old. Among the 641 children, a total of $386 \mathrm{~S}$. pneumoniae isolates were detected from 376 (59\%) participants $(223 / 376[59 \%] \leq 24$ months and $153 / 376$ [41\%] $>24$ months $(P<0.001))$. Among the 386 isolates obtained, $359(93 \%)$ were isolated from NP samples, 22 $(6 \%)$ were isolated from OP $(P<0.05)$ and $5(1 \%)$ were isolated in both reservoirs but had a different serotype isolates.

Among the 386 positive NP or OP samples, 229 (59\%) samples were obtained among children $\leq 24$ months of age (mean age: 13 months) and 157 (41\%) samples were from children $>$ than 24 months of age (mean age: 35 months $)(P<0.001)$.

\subsection{Streptococcus pneumoniae Serotypes}

Among the 386 S. pneumoniae isolates, 346 (90\%) were serotyped. Table 1 shows the distribution of S. pneumoniae serotypes identified. Of the identified serotypes, only serotype 3 was significantly different between the age groups. Overall cumulative PCV-13 serotypes and non-PCV13 serotypes were different between the age groups. As a group, non-PCV13 serotypes were more common in the younger age group than in children $>24$

Table 1. S. pneumoniae serotype distribution among isolates obtained from the nasopharynx and/or oropharynx in Costa Rican children with otitis media, between years 2002 and 2006, according to age group.

\begin{tabular}{|c|c|c|c|}
\hline $\begin{array}{c}\text { Total number of } \\
\text { serotyped } \\
\text { S. pneumoniae strains } \\
\end{array}$ & $\begin{array}{l}\text { Age group } \leq 24 \\
\text { months }\end{array}$ & $\begin{array}{l}\text { Age group }>24 \\
\text { months }\end{array}$ & $P$ value \\
\hline 346 & 203 & 143 & \\
\hline \multicolumn{4}{|c|}{ PCV-7 serotypes } \\
\hline 4 & $3(1.5)^{\mathrm{a}}$ & $3(2.1)$ & 0.6 \\
\hline 14 & $22(10.8)$ & $19(13.3)$ & 0.5 \\
\hline $19 \mathrm{~F}$ & $46(22.7)$ & $29(20.3)$ & 0.6 \\
\hline $23 \mathrm{~F}$ & $13(6.4)$ & $17(11.9)$ & 0.1 \\
\hline $6 \mathrm{~B}$ & $29(14.3)$ & $14(9.8)$ & 0.2 \\
\hline $9 \mathrm{~V}$ & $3(1.5)$ & $5(3.5)$ & 0.2 \\
\hline $18 \mathrm{C}$ & $4(2)$ & $2(1.4)$ & 1 \\
\hline $\begin{array}{c}\text { Cumulative number of } \\
\text { isolates included in } \\
\text { PCV } 7\end{array}$ & $120(59.1)$ & $89(62.2)$ & 0.6 \\
\hline \multicolumn{4}{|c|}{ PCV-10 serotypes } \\
\hline 1 & $1(0.5)$ & $1(0.7)$ & 1 \\
\hline 5 & $0(0)$ & $1(0.7)$ & 0.2 \\
\hline $7 \mathrm{~F}$ & $1(0.5)$ & $0(0)$ & 0.2 \\
\hline $\begin{array}{c}\text { Cumulative number of } \\
\text { isolates included in } \\
\text { PCV } 10\end{array}$ & $122(60.1)$ & $91(63.6)$ & 0.5 \\
\hline \multicolumn{4}{|c|}{ PCV-13 serotypes } \\
\hline 3 & $11(5.4)$ & $18(12.6)$ & 0.03 \\
\hline $6 \mathrm{~A}$ & $9(4.4)$ & $6(4.2)$ & 0.8 \\
\hline $19 \mathrm{~A}$ & $3(1.5)$ & $2(1.4)$ & 1 \\
\hline $\begin{array}{c}\text { Cumulative number of } \\
\text { isolates included in } \\
\text { PCV } 13 \\
\end{array}$ & $145(71.4)$ & $117(81.8)$ & 0.03 \\
\hline \multicolumn{4}{|c|}{ Nonvaccine serotypes isolated } \\
\hline $\begin{array}{c}13,28,34,48,10 \mathrm{~A}, 10 \mathrm{~B}, \\
11 \mathrm{~A}, 11 \mathrm{~F}, 15 \mathrm{~A}, 15 \mathrm{~B}, 15 \mathrm{C} \\
15 \mathrm{~B} / \mathrm{C}, 16 \mathrm{~F}, 17 \mathrm{~F}, 18 \mathrm{~A}, \\
18 \mathrm{~F}, 19 \mathrm{~V}, 35 \mathrm{~B}, 35 \mathrm{~F}, 6 \mathrm{C} \\
9 \mathrm{~A}, 9 \mathrm{~L}, 9 \mathrm{~N}, 24 \mathrm{~F}, 38,45 \mathrm{~B}\end{array}$ & $58(28.6)$ & $26(18.2)$ & 0.04 \\
\hline
\end{tabular}

${ }^{\mathrm{a}}$ Numbers in parentheses, percent. 
months old.

\subsection{Antimicrobial Susceptibility}

Minimal inhibitory concentration (MIC) values for the different antimicrobials tested among S. pneumoniae serotypes included in the three conjugated vaccines are shown in Table 2. Children $\leq 24$ months (203/346 [59\%]) had statistically significantly more antimicrobial non-susceptible isolates than children $>24$ months of age $(143 /$ $346[41 \%])(P<0.001)$.

Penicillin non-susceptibility serotypes included in the three conjugated $S$. pneumoniae vaccines $(\mathrm{PCV}-7$, PCV10 and PCV-13) were: $57 \%$ in children $\leq 24$ months versus a $38 \%$ in older children $(P<0.001)$.

\subsection{Multidrug Resistance (MDR)}

Among the 346 serotyped isolates, 53 (15\%) strains belonging to only 10 serotypes were considered MDR: $4 \%$ (2/53) of these MDR strains were non-PCV 13 serotypes and 96\% (51/53) were PCV-13 $(P<0.001)$, Table 3 describes the MDR vaccine-type distribution and their antimicrobial resistance.

\subsection{Potential Vaccine Coverage}

Potential coverage with the conjugated vaccines, PCV-7,
PCV-10 and PCV-13, for the overall study population was: $60 \%, 62 \%$ and $76 \%$ respectively, with PCV-13 showing statistical significantly increased vaccine coverage than that observed with PCV-7 $(P<0.001)$ or PCV-10 $(P<0.001)$.

Potential vaccine coverage against penicillin non-susceptible isolates was as follows: PCV-7: 59\%, PCV-10: 60\% and PCV-13: 74\% (PCV-7 vs. PCV-10: P: 0.8; PCV-10 vs. PCV-13: $P<0.001$; PCV-7 vs. PCV-13: $P<$ $0.001)$. Potential vaccine coverage against MDR serotypes were as follows: PCV-7: 44/53 (83\%), PCV-10: 45/53 (85\%) and PCV-13: 51/53 (96\%) (PCV-7 vs. PCV-10: P: 0.8; PCV-10 vs. PCV-13: P: 0.04; PCV-7 vs. PCV-13: $P: 0.03)$.

\section{Discussion}

Streptococcus pneumoniae is the most common cause of vaccine preventable death in children less than 5 years of age globally. In Costa Rica, it is also the most frequent pathogen detected in patients with OM [32].

In the present study, S. pneumoniae colonization of the upper respiratory tract in children with OM was analyzed, $59 \%$ of the patients harbor this isolate in the NP or OP. Similar to previous studies, this study demonstrates that the vast majority of colonizing strains were isolated from the $\mathrm{NP}$ in comparison to the OP $(93 \%$ versus $7 \%$, respec-

Table 2. Minimal inhibitory concentration $(\mu \mathrm{g} / \mathrm{ml})$ values among vaccine-type Streptococcus pneumoniae strains isolated from the nasopharynx and or oropharynx of Costa Rican children with otitis media, during 2002-2006.

\begin{tabular}{|c|c|c|c|c|c|c|c|c|c|c|c|c|c|c|c|}
\hline \multirow{3}{*}{ SEROTYPES } & \multicolumn{4}{|c|}{ Amoxicillin } & \multicolumn{2}{|c|}{ AM-CL } & \multicolumn{3}{|c|}{ Ceftriaxone } & \multicolumn{3}{|c|}{ Levofloxacin } & \multicolumn{3}{|c|}{ Penicillin } \\
\hline & \multicolumn{15}{|c|}{ PCV-7 Serotypes } \\
\hline & $\mathbf{N}^{\mathbf{a}}$ & $\operatorname{MIC50}^{\mathrm{b}}$ & $\operatorname{MIC90}^{c}$ & $\mathbf{N}$ & MIC50 & MIC90 & $\mathbf{N}$ & MIC50 & MIC90 & $\mathbf{N}$ & MIC50 & MIC90 & $\mathbf{N}$ & MIC50 & MIC90 \\
\hline 4 & 6 & 0.125 & 0.125 & 6 & 0.125 & 0.125 & 6 & 0.125 & 0.125 & 6 & 0.500 & 1.000 & 6 & 0.125 & 0.125 \\
\hline $6 \mathrm{~B}$ & 42 & 0.125 & 0.125 & 42 & 0.125 & 0.125 & 42 & 0.125 & 0.125 & 42 & 0.500 & 1.000 & 42 & 0.125 & 0.125 \\
\hline $9 \mathrm{~V}$ & 8 & 0.125 & 0.125 & 8 & 0.125 & 0.125 & 8 & 0.125 & 0.125 & 8 & 0.500 & 1.000 & 7 & 0.125 & 0.125 \\
\hline 14 & 41 & 0.125 & 0.125 & 41 & 0.125 & 0.125 & 41 & 0.125 & 0.250 & 40 & 1.000 & 1.000 & 41 & 0.125 & 0.125 \\
\hline $18 \mathrm{C}$ & 6 & 0.125 & 1.0 & 6 & 0.125 & 1 & 6 & 0.125 & 0.500 & 6 & 1.000 & 1.000 & 6 & 0.125 & 2.000 \\
\hline $19 \mathrm{~F}$ & 74 & 0.125 & 1.0 & 74 & 0.125 & 1 & 74 & 0.125 & 1.000 & 74 & 1.000 & 1.000 & 73 & 0.125 & 2.000 \\
\hline $23 \mathrm{~F}$ & 30 & 0.125 & 1.0 & 30 & 0.125 & 2.0 & 30 & 0.250 & 2.000 & 30 & 1.000 & 1.000 & 30 & 1.000 & 2.000 \\
\hline \multicolumn{16}{|c|}{ PCV-10 Serotypes } \\
\hline 1 & 2 & 0.125 & 0.125 & 2 & 0.125 & 0.125 & 2 & 0.125 & 0.125 & 2 & 0.500 & 0.500 & 2 & 0.125 & 0.125 \\
\hline 5 & 1 & 0.125 & 0.125 & 1 & 0.125 & 0.125 & 1 & 0.125 & 0.125 & 1 & 1.000 & 1.000 & 1 & 0,125 & 0.125 \\
\hline $7 F$ & 1 & 0.125 & 0,125 & 1 & 0.125 & 0.125 & 1 & 0.125 & 0.125 & 1 & 0.500 & 0.500 & 1 & 0.125 & 0.125 \\
\hline \multicolumn{16}{|c|}{ PCV-13 Serotypes } \\
\hline $19 \mathrm{~A}$ & 4 & 0.125 & 1.000 & 4 & 0.125 & 1.000 & 4 & 0.125 & 1.000 & 4 & 1.000 & 1.000 & 4 & 0.125 & 2.000 \\
\hline 3 & 27 & 0.125 & 0.125 & 27 & 0.125 & 0.125 & 27 & 0.125 & 0.125 & 27 & 0.500 & 0.500 & 27 & 0.125 & 0.125 \\
\hline $6 \mathrm{~A}$ & 15 & 0.125 & 0.125 & 15 & 0.125 & 0.125 & 15 & 0.125 & 0.125 & 15 & 0.500 & 1.000 & 15 & 0.125 & 0.125 \\
\hline
\end{tabular}

${ }^{\mathrm{a}}$ Number of isolates tested; ${ }^{\mathrm{b}}$ Minimal inhibitory concentration for $50 \%$ of the strains; ${ }^{\mathrm{c}}$ Minimal inhibitory concentration for $90 \%$ of the strains. 
Table 3. Multidrug resistance among vaccine-type Streptococcus pneumoniae strains isolated from the nasopharynx and/or oropharynx of Costa Rican children with otitis media, during 2002-2006.

\begin{tabular}{|c|c|c|c|c|}
\hline MDR*S. pneumoniae serotype & $\begin{array}{l}\text { Total number of } S \text {. pneumoniae } \\
\text { strains isolated per serotype }\end{array}$ & $\begin{array}{l}\text { Total number of } \mathrm{MDR}^{\mathrm{a}} \\
\text { S. pneumoniae strains }\end{array}$ & $\begin{array}{c}\text { MDR } \\
\text { percentage }\end{array}$ & $\begin{array}{l}\text { Antimicrobia } \\
\text { resistance }\end{array}$ \\
\hline $19 \mathrm{~A}$ & 5 & 3 & $60 \%$ & $\begin{array}{l}\text { Penicillin } \\
\text { Amoxicillin } \\
\text { AM-CL } \\
\text { Ceftriaxone } \\
\text { Erythromycin } \\
\text { TPM/SMX }\end{array}$ \\
\hline 1 & 2 & 1 & $50 \%$ & $\begin{array}{l}\text { Penicillin } \\
\text { Erythromycin } \\
\text { TMP/SMX }\end{array}$ \\
\hline 14 & 41 & 19 & $46 \%$ & $\begin{array}{l}\text { Ceftriaxone } \\
\text { Penicillin } \\
\text { Erythromycin } \\
\text { TMP/SMX }\end{array}$ \\
\hline $9 \mathrm{~V}$ & 8 & 2 & $25 \%$ & $\begin{array}{l}\text { Ceftriaxone } \\
\text { Penicillin } \\
\text { TMP/SMX }\end{array}$ \\
\hline $6 \mathrm{~A}$ & 15 & 3 & $20 \%$ & $\begin{array}{l}\text { Penicillin } \\
\text { Ceftriaxone } \\
\text { Erythromycin } \\
\text { TMP/SMX }\end{array}$ \\
\hline $6 \mathrm{~B}$ & 43 & 8 & $19 \%$ & $\begin{array}{l}\text { Penicillin } \\
\text { Erythromycin } \\
\text { TMP/SMX }\end{array}$ \\
\hline $19 \mathrm{~F}$ & 75 & 12 & $16 \%$ & $\begin{array}{l}\text { Ceftriaxone } \\
\text { Penicillin } \\
\text { Erythromycin } \\
\text { TMP/SMX }\end{array}$ \\
\hline $23 \mathrm{~F}$ & 30 & 3 & $10 \%$ & $\begin{array}{l}\text { Ceftriaxone } \\
\text { Penicillin } \\
\text { Erythromycin } \\
\text { TMP/SMX }\end{array}$ \\
\hline
\end{tabular}

${ }^{\mathrm{a}}$ MDR: Multi-Drug Resistant Isolates.

tively; $P<0.001$ ), but that $7 \%$ of isolates would have been missed if OP cultures were not performed [33-37].

Incidence of colonization, mucosal and invasive disease caused by $S$. pneumoniae varies by gender, season and age group [36]. In our study and as previously described in other studies $[5,6,10,36]$, children $<24$ months of age had significantly higher rates of $S$. pneumoniae colonization than children older than 24 months $(59 \%$ versus $41 \%$, respectively; $P<0.001)$. The most common $\mathrm{NP}$ and/or OP S. pneumoniae serotypes obtained in this group of Costa Rican children with OM were: 19F, 6B, $14,23 \mathrm{~F}$ and 3 , comprising $59.6 \%$ of the total strains serotyped. The current analysis indicates that in Costa Rica, during the study period, the most frequent colonizing serotype isolated from children at all ages with OM was serotype 19F. These data correlates with previous studies performed in Costa Rican children since 1999 where serotype $19 \mathrm{~F}$ was also the most common serotype isolated from the middle ear fluid of children with OM [32$36,38]$.

The individual serotype distribution was similar among age groups, except for serotype 3, which was significantly more frequent among children $>24$ months of age than among children $\leq$ than 24 months of age. Serotypes isolated in children $<24$ months of age had a statistically significant higher rate of penicillin resistance than those from children $>24$ months of age. The higher antimicrobial resistance rates in the younger population is similar to previous studies [17-19,21] and also correlates with higher resistance rates observed in S. pneumoniae strains obtained from the middle ear fluid from children $\leq 24$ months of age, and supports the need for pneumococcal conjugate vaccination in this age group $[6,35,36]$.

Although serotype 19A was not a frequent pathogen during the study period ( 5 isolates), it was the most frequent MDR serotype (60\%).

Overall potential vaccine protection against the NP and/or OP S. pneumoniae serotypes isolated in this study from Costa Rican children with $\mathrm{OM}$ were higher with PCV13 (76\%) than that with PCV-10 (62\%) or PCV-7 (60\%). This difference was mainly driven by the frequency of serotype 3 and the small numbers of serotypes 
$1,5,19 \mathrm{~A}$ and $7 \mathrm{~F}$ found. This parallels the serotypes found in OM where serotype 3 is frequent and serotypes 1 and 5 are rarely found as causes of OM, although they can cause invasive disease.

PCV-13 also showed higher serotype coverage rates against penicillin-resistant strains and MDR strains (74\% and $96 \%$, respectively) than PCV-10 (60\% and $85 \%$, respectively) and PCV-7 (59\% and 83\% respectively).

To our knowledge, this study represents the largest Latin America set of data analyzing the distribution of $S$. pneumoniae serotypes obtained from the NP and/or OP of children with OM before the introduction of PCV-7 into the NIP of Costa Rica and following a limited use of PCV-7 into a limited cohort of children. This study serves as a baseline for evaluation of impact of the introduction of PCVs into the Costa Rican NIP.

Currently, three PCVs are in use in Latin America (PCV-7, PCV-10 and PCV-13). Our data analyzing the serotype distribution of $S$. pneumoniae serotypes colonizing the NP and/or OP of Costa Rican children with OM suggest that, similar to the analysis performed among middle ear fluid isolates in the same population [39], PCV-13 offers the broadest protection against $S$. pneumoniae strains isolated in this population.

Following the introduction of PCV-13 into the NIP of Costa Rica in 2011, further studies will evaluate the S. pneumoniae serotype dynamics and antimicrobial susceptibility patterns in the NP and/or OP of Costa Rican children.

\section{REFERENCES}

[1] J. A. Willians, E. Gouvs, C. Bosghi-Pinto, J. Brice and C. Dye, "Estimates of World-Wide Distribution of Child Deaths from Acute Respiratory Infections," Lancet Infectious Diseases, Vol. 2, No. 1, 2002, pp. 25-35. doi:10.1016/S1473-3099(01)00170-0

[2] D. Bogoaert, R. De Groot and P. W. Hermans, "Streptococcus pneumonia Colonization: The Key to the Pneumococcal Disease," Lancet Infectious Diseases, Vol. 4, No. 3, 2004, pp. 144-154. doi:10.1016/S1473-3099(04)00938-7

[3] R. Dagan, E. Leibovitz, D. Greenberg, P. Yagupsky, D. M. Fliss and A. Leiberman, "Dynamics of Pneumococcal Nasopharyngeal Colonization during the First Days of Antibiotic Treatment in Pediatric Patients," The Pediatric Infectious Disease Journal, Vol. 17, No. 10, 1998, pp. 880-885. doi:10.1097/00006454-199810000-00006

[4] L. Igvarsson, K. Lundgren and L. Ursing, "Bacterial Flora in the Nasopharynx in Healthy Children," Actas Otolaryngologica, Vol. 93, No. S386, 1982, pp. S94-S96. doi:10.3109/00016488209108482

[5] G. Anianson, B. Alm, B. Anderson, et al., "Nasopharyngeal Colonization during the First Year of Life," Journal of Infectious Diseases, Vol. 165, No. S1, 1992, pp. 8-41.

[6] R. Dagan, R. Melamed, M. Muallem and P. Yagupsky, "Nasopahryngeal Colonization in Southern Israel with Antibiotic Resistant Pneumococci during the First 2 Years of
Life: Relation to Serotypes Likely to Be Included in Pneumococcal Conjugate Vaccines," Journal of Infectious Diseases, Vol. 174, No. 6, 1996, pp. 1352-1355. doi:10.1093/infdis/174.6.1352

[7] K. P. Klugman, H. J. Koornhof, A. Wasas, K. Storey and I. Gilbertson, "Carriage of Penicillin-Resistant Pneumococci," Archives of Disease in Childhood, Vol. 61, No. 4, 1986, pp. 377-381. doi:10.1136/adc.61.4.377

[8] T. D. Mastro, N. K. Nomani, Z. Ishaq, et al., "Use of Nasopharyngeal Isolates of Streptococcus pneumoniae and Haemophilus influenzae from Children in Pakistan for Surveillance for Antimicrobial Resistance," The Pediatric Infectious Disease Journal, Vol. 12, No. 10, 1993, pp. 824-830. doi:10.1097/00006454-199310000-00006

[9] E. N. Berezin, M. D. Cardenuto, L. L. Ferreira, et al., "Distribution of Streptococcus pneumoniae Serotypes in Nasopharyngeal Carriage and in Invasive Pneumococcal Disease in Sao Paulo, Brazil," The Pediatric Infectious Disease Journal, Vol. 26, No. 7, 2007, pp. 643-644. doi:10.1097/INF.0b013e3180616d0f

[10] M. Vives, M. Garcia, P. Saenz, M. Mora, L. Mata, et al., "Nasopharyngeal Colonization in Costa Rican Children during the First Year of Life," The Pediatric Infectious Disease Journal, Vol. 16, No. 9, 1997, pp. 852-858. doi:10.1097/00006454-199709000-00007

[11] E. V. Millar, K. L. O. Brien, E. R. Zell, et al., "Nasopharyngeal Carriage of Streptococcus pneumoniae in Navajo and White Mountain Apache Children before Introduction of Pneumococcal Conjugate Vaccine," The Pediatric Infectious Disease Journal, Vol. 28, No. 8, 2009, pp. 711716. doi:10.1097/INF.0b013e3181a06303

[12] B. M. Gray, G. M. Converse and H. C. Dillon, "Epidemiologic Studies of Streptococcus pneumonia in Infants: Acquisition, Carriage, and Infection during the First 24 Months of Life," Journal of Infectious Diseases, Vol. 142, No. 6, 1980, pp. 923-933. doi:10.1093/infdis/142.6.923

[13] R. K. Syrjanen, T. M. Kilpi, T. H. Kaijalainen, et al., "Naso- pharyngeal Carriage of Streptococcus pneumoniae in Finnish Children Younger than 2 Years Old," Journal of Infectious Diseases, Vol. 184, No. 4, 2001, pp. 451-459. doi: $10.1086 / 322048$

[14] C. Coles, R. Kanungo, L. Rahmathullah, et at., "Pneumococcal Nasopharyngeal Colonization in Young South Indian Infants," The Pediatric Infectious Disease Journal, Vol. 20, No. 3, 2001, pp. 289-7295. doi:10.1097/00006454-200103000-00014

[15] M. Gratten, H. Gratten, A. Poil, et al., "Colonization of Influenza and Streptococcus pneumoniae in the Upper Respiratory Tract of Neonates in Papua New Guinea: Primary Acquisition, Duration of Carriage and Relationship to Carriage in Mothers," Biology of the Neonate, Vol. 50, No. 2, 1986, pp. 114-120. doi:10.1159/000242576

[16] H. Goossens, M. Ferech, R. Vnder Stichele and M. Elseviers, "Outpatient Antibiotic Use in Europe and Association with Resistance: A Cross National Database Study," Lancet, Vol. 365, No. 9459, 2005, pp. 579-587.

[17] F. Baquero and E. Loza, "Antibiotic Resistance of Microorganisms Involved in Ear, Nose and Throat Infections," The Pediatric Infectious Disease Journal, Vol. 174, 1994, 
pp. 1352-1355.

[18] P. C. Appelbaum, "Epidemiology and in Vitro Susceptibility of Drug-Resistance Streptococcus pneumoniae," The Pediatric Infectious Disease Journal, Vol. 15, No. 10, 1996, pp. 932-939.

doi:10.1097/00006454-199610000-00030

[19] K. P. Klugman, "Efficacy of Pneumococcal Conjugate Vaccines and Their Effect on Carriage and Antimicrobial Resistance," Lancet Infectious Diseases, Vol. 1, No. 2, 2001, pp. 85-91. doi:10.1016/S1473-3099(01)00063-9

[20] C. G. Whitney, M. M. Farley, J. Hadler, et al., "Increasing Prevalence of Multidrug-Resistant Streptococcus pneumoniae in the United States," The New England Journal of Medicine, Vol. 343, No. 26, 2000, pp. 19171924. doi:10.1056/NEJM200012283432603

[21] R. Dagan, N. Givon-Lavi, O. Zamir, et al., "Reduction of Nasopharyngeal Carriage of Streptococcus pneumoniae after Administration of a 9-Valent Pneumococcal Conjugate Vaccine to Toddlers Attending Day Care Centers," Journal of Infectious Diseases, Vol. 185, No. 7, 2002, pp. 927-936. doi: $10.1086 / 339525$

[22] R. Dagan, R. Melmed, M. Muallem, et al., "Reduction of Nasopharyngeal Carriage of Pneumococcci during the Second Year of Life by the Heptavalent Conjugate Pneumococcal Vaccine," Journal of Infectious Diseases, Vol. 174, No. 6, 1996, pp. 1271-1278. doi:10.1093/infdis/174.6.1271

[23] R. Dagan, R. Melmed, M. Muallem, R. Melamed, O. Leroy and P. Yagupsky, "Reduction of Pneumococcal Nasopharyngeal Carriage in Early Infancy after Immunization with Tetravalent Pneumococcal Vaccines Conjugated to Either Tetanus Toxoid or Diphtheria Toxoid," The Pediatric Infectious Disease Journal, Vol. 16, No. 11, 1997 , pp. 1060-1064. doi:10.1097/00006454-199711000-00011

[24] N. Mbelle, R. E. Huebner, A. D. Wasas, A. Kimura, I. Chang and K. P. Klugman, "Inmunogenicity and Impact on Nasopharyngeal Carriage of a Nonavalent Pneumococcal Conjugate Vaccine," Journal of Infectious Diseases, Vol. 180, No. 4, 1999, pp. 1171-1176. doi:10.1086/315009

[25] S. K. Obaro, R. A. Adegbola, W. A. Banya and B. M. Greenwood, "Carriage of Pneumococci after Pneumococcal Vaccination," Lancet, Vol. 348, No. 9022, 1996, pp. 271-272. doi:10.1016/S0140-6736(05)65585-7

[26] R. Dagan, N. Givon-Lavi, O. Zamir and D. Fraser, "Effect of a Nonavalent Conjugate Vaccine on Carriage of Antibiotic-Resistant Streptococcus pneumoniae in DayCare Centers," The Pediatric Infectious Disease Journal, Vol. 22, No. 6, 2003, pp. 532-540. doi:10.1097/01.inf.0000069761.11093.c3

[27] N. Givon-Lavi, D. Fraser and R. Dagan, "Vaccination of Day-Care Center Attendees Reduces Carriage of Streptococcus pneumoniae among Younger Siblings," The Pediatric Infectious Disease Journal, Vol. 22, No. 6, 2003, pp. 524-532. doi:10.1097/01.inf.0000069760.65826.f2

[28] K. L. O. Brien and R. Dagan, "The Potential Indirect Effect of Conjugate Pneumococcal Vaccines," Vaccine, Vol. 21, No. 17-18, 2003, pp. 1815-1825.
doi:10.1016/S0264-410X(02)00807-1

[29] L. Temine, D. Guillemont and P. Y. Boelle, "Short and Long Term Effects of Pneumococcal Conjugate Vaccination of Children on Penicillin Resistance," Antimicrobial Agents and Chemotherapy, Vol. 48, No. 6, 2004, pp. 2206-2213. doi:10.1128/AAC.48.6.2206-2213.2004

[30] National Committee for Clinical Laboratory Standards, "Performance Standards for Antimicrobial Susceptibility Testing," 12th Informational Supplement. NCCLS Document M100-512, Wayne, 2002.

[31] R. Austrian, "The Quellung Reaction, a Neglected Microbiologic Tecnique," Mount Sinai Journal of Medicine, Vol. 43, No. 6, 1976, pp. 699-709.

[32] A. Arguedas, et al., "Middle Ear Fluid Streptococcus pneumoniae Serotype Distribution in Costa Rican Children with Otitis Media," The Pediatric Infectious Disease Journal, Vol. 24, No. 7, 2005, pp. 631-634. doi:10.1097/01.inf.0000168748.92510.45

[33] A. Arguedas, R. Dagan, C. Soley, C. Loaiza, K. Knudsen, N. Porat, A. Pérez, E. Brilla and M. L. Herrera, "Microbiology of Otitis Media in Costa Rican Children, 1999 through 2001," The Pediatric Infectious Disease Journal, Vol. 22, No. 12, 2003, pp. 1063-1068. doi:10.1097/01.inf.0000101189.81501.e9

[34] A. Arguedas, C. Loaiza, A. Perez, et al., "Microbiology of Otitis Media in Costa Rican Children," The Pediatric Infectious Disease Journal, Vol. 17, No. 8, 1998, pp. 680689. doi:10.1097/00006454-199808000-00004

[35] S. Guevara, C. Soley, A. Arguedas, N. Porat and R. Dagan, "Seasonal Distribution of Otitis Media Pathogens among Costa Rican Children," The Pediatric Infectious Disease Journal, Vol. 27, No. 1, 2008, pp. 12-16. doi:10.1097/INF.0b013e3181468643

[36] A. Arguedas, R. Dagan, S. Guevara, et al., "Middle Ear Fluid Streptococcus pneumoniae Serotype. Distribution in Costa Rican Children with Otitis Media," The Pediatric Infectious Disease Journal, Vol. 24, No. 7, 2005, pp. 631634. doi:10.1097/01.inf.0000168748.92510.45

[37] D. Greenberg, et al., "Nasopharyngeal Carriage of Individual Streptococcus pneumoniae Serotypes during Pediatric Pneumonia as a Means to Estimate Serotype Disease Potential," The Pediatric Infectious Disease Journal, Vol. 30, No. 3, 2011, pp. 227-233. doi:10.1097/INF.0b013e3181f87802

[38] L. Aguilar, O. Alvarado, C. Soley, A. Abdelnour, R. Dagan and A. Arguedas, "Microbiology of the Middle Ear Fluid in Costa Rican Children between 2002 and 2007," International Journal of Pediatric Otorhinolaryngology, Vol. 73, No. 10, 2009, pp. 1407-1411. doi:10.1016/j.ijporl.2009.07.005

[39] S. Guevara, A. Abdelnour, C. Soley, N. Porat, R. Dagan and A. Arguedas, "Streptococcus pneumoniae Serotypes Isolated from the Middle Ear Fluid of Costa Rican Children Following Introduction of the Heptavalent Pneumococcal Conjugate Vaccine into a Limited Population," Vaccine, Vol. 30, No. 26, 2012, pp. 3857-3861. doi:10.1016/j.vaccine.2012.04.010 